\title{
Pontocerebellar hypoplasia type 1
}

\author{
INSERM
}

\section{Source}

INSERM. (1999). Orphanet: an online rare disease and orphan drug data base.

Pontocerebellar hypoplasia type 1. ORPHA:2254

Pontocerebellar hypoplasia type 1 (PCH1), also known as Norman's disease, is a clinically and genetically heterogeneous group of autosomal recessive disorders with a prenatal onset characterized by diffuse muscular atrophy secondary to pontocerebellar hypoplasia and spinal cord anterior horn cell degeneration resulting in early death. 